Running Head: USING SIMSCHOOL IN RURAL SETTINGS

SimSchool: An Opportunity for Using Serious Gaming for Training Teachers in Rural Areas

Tandra Tyler-Wood

Mary Estes

Rhonda Christensen

Gerald Knezek

University of North Texas

David Gibson

Curtin University, Australia 


\begin{abstract}
This article examines the use of simSchool as a training tool for educators working with students with special needs in rural districts. SimSchool is a game which emulates a classroom utilizing a virtual environment. The theory supporting simSchool is explored and current research associated with simSchool is reviewed. The issues surrounding retaining quality special educators in rural districts are discussed. The potential for using simSchool for working with rural special education teachers is explored.
\end{abstract}




\section{SimSchool: An Opportunity for Using Serious Gaming for Training Teachers in Rural Areas}

In recent years, serious gaming has emerged as a potential training tool for educating adults. Serious gaming can be defined as "a mental contest, played with a computer in accordance with specific rules, that uses entertainment to further government, corporate, education, health, public policy or strategic communications training" (Zyda, 2005). Some examples of themes of serious games include driver's education, military training, and cultural awareness, but the breadth of potential themes is limitless (Backlund, Engstrom, Johannesson, \& Lebram, 2010; Fowler \& Pusch, 2010; Reckien \& Eisenack, 2010; Smith, 2010).

\section{Uses for simSchool}

This article will explore the use of simSchool as a training option for special educators working with students in rural settings. SimSchool is an internet- based simulation program that simulates a classroom. SimSchool has the potential to change the way pre-service teachers are trained, as well as offer inservice training opportunities for educators working in rural settings. In addition to its many standard features, such as varying the number of students in the classroom and choosing from a variety of preset classroom tasks, the program allows users to create custom students. Any number of exceptionalities can be depicted within the simclassroom, including mental and physical disabilities, allowing users to practice teaching diverse learners. Lesson plans and tasks can be just as varied, providing simSchool users with freedom and creativity very similar to what they will experience in the real classroom. Readers wishing to learn more about simSchool can visit http://simschool.net/help/start.php, or go to https://simschool.org/my/register to try simschool for free.

In the simulated classroom, divergent populations and students with disabilities can be emulated. The simSchool program 
provides teachers with a "virtual practicum" to develop their teaching skills prior to teaching in real classrooms. The program aims to enable users to develop skills in differentiating instruction, classroom management, working with special needs learners and adapting instruction to multiple cognitive abilities. Within the last few years, simSchool users have been developing and housing lesson plans from various disciplines to allow players to interact with subject specific curricula and students with disabilities simultaneously.

Because pre-service teachers can practice with a much wider variety of students than they are likely to encounter during their internships in real classrooms, simSchool has the potential to provide a comprehensive training experience. In addition to facilitating training for inclusion, in which learners with special needs are educated alongside general education students, simSchool can be used to facilitate training in the areas of lesson planning and sequencing, behavior management, and assessing student learning, among others.

Future teachers or current teachers can practice teaching in an inclusive classroom with a variety of divergent learners, including students with disabilities. An overarching goal of simSchool is to optimize training opportunities for teachers, so that teachers have the opportunity to work with a wide range of learners prior to student teaching or early on in their educational career. A beginning teacher in a rural district may have little if any experience with educating a student with low incidence disabilities such as hearing impairment. SimSchool provides an option for the beginning teacher to gain experience with learners with uncommon disabilities, with a goal of increasing teacher efficacy as well as student learning.

\section{Need}

The US faces a critical shortage of highly trained teachers in rural areas (Barnet \& Hirsch, 2005). Studies have indicated that 
high-quality staff development programs lead to improved classroom teaching and employee retention, especially in small and rural schools (Rural Policy Matters, 2001). Lowe (2006) indicates that many of these efforts to improve classroom teaching are hindered due to a shortage of funding, release time for staff participation, and an overall lack of program results. SimSchool provides an inexpensive, alternative option for training teachers in rural settings. SimSchool is available at any time of the day or night because it is online.

Erickson, Noonan, and McCall (2012) indicate that it is particularly difficult for special educators to access and implement research-based practices due to a lack of professional development and limited interactions with colleagues with expertise. These researchers indicate that online professional development can alleviate these challenges by virtually connecting rural special education teachers with both institutions of higher education and rural peer teachers as they learn about, discuss, and implement research-based strategies.

\section{Opportunities Offered to Rural Schools Through simSchool}

SimSchool provides a platform for providing teacher training. Other career areas such as pilot training and the medical field have used simulation to provide a plethora of training experience in a "safe" simulated environment. SimSchool can provide "safe training" options for training rural teachers.

Gherke and McCoy (2007) indicate that rural schools continue to struggle with the recruitment and retention of qualified special education teachers. Beginning special educators are two and one half times more likely to leave their positions than their general education counterparts. Special educators in rural settings often provide instruction in a variety of settings to students with a wide range of educational needs in multiple disability categories, and experience geographic barriers that may hinder their access to 
specialists or major resource centers (Billingsley, Carlson, \& Klein, 2004).

By providing an opportunity for appropriate training, access to lesson plans, and an option for interacting in an online community, simSchool can be a tool for offering support for rural teachers. SimSchool fits well into an online training program. Experience working with students with disabilities can be provided for rural teachers through simSchool. SimSchool can be an effective device for providing the skills to assist teachers with meeting with success in the classroom. Successful teachers are more likely to remain in teaching (Gherke \& McCoy, 2007).

Erikson, Noonan, and McCall (2012) indicate that retaining teachers and accessing professional development have been longstanding struggles for rural school districts. Particular challenges include retaining teachers with special education endorsements. These researchers found that teachers who participated in online professional development gained knowledge, increased personal capacity to apply research-based practices, and implemented research-based transition practices within their classrooms. SimSchool fits well into an online training program for rural educators.

According to Willams, Martin, and Hess (2010), students with disabilities in rural settings are more likely to receive their instruction in general education settings, when compared to their counterparts in urban or suburban settings. Several reasons are cited for these differences including small schools, fewer students with disabilities, and a lack of resources, including qualified teachers. These issues often result in students with disabilities receiving services in general education classrooms with teachers with limited experience with special populations and limited supporting resources. Therefore, it is particularly important that general education teachers, as well as special education teachers, in rural settings receive training on working with students with disabilities. Through a virtual teaching environment, simSchool 
allows an opportunity for teachers to gain experience with many types of students, including students with disabilities.

Johnson, Humphrey, and Allred (2009) describe a promising model utilizing guided experiential learning to support the training, recruitment and retention of special education teachers in rural areas. The approach draws on several bodies of research to include best practices for teacher education, online service delivery, collaboration among key stakeholders, and the development of strong mentoring and induction programs.

SimSchool provides a platform for mentoring as well as options for incorporating lessons into an induction program.

\section{Research Supporting simSchool}

Research on simSchool has been supported by the United States Department of Education, the National Science Foundation, and Educause. Some of the findings gathered through that research are presented below.

McPherson, Tyler-Wood, McEnturff and Peak (2011) found that pre-service teachers who participated in simSchool, when compared to control group pre-service teachers, scored higher on self-reported measures of teacher preparation. In addition, simSchool participants valued simulations and computer games more when compared to a control group.

Bush and Hall (2013) found that simSchool provided a flexible, cost beneficial, and safe learning environment for preservice teachers. By providing a supplement to physical field experiences, simSchool encouraged a participatory system that increased teacher-student interactions.

Peak et al (2009) found that special education pre-service teachers who participated in simSchool felt better prepared to enter the teaching field. 
Hopper, Knezek, and Christensen (2013) found that after participating in simSchool, pre-service teachers' self-appraisal of teaching experience improved while their confidence in their teaching abilities became more in line with their experience .

\section{Theories Supporting simSchool}

SimSchool synthesizes theoretical frameworks of instructional leadership, interpersonal psychology, and behaviorist teaching models into a computer simulation. In the simulation, the player takes on the role of a teacher and interacts with virtual students. The choices selected by the player affect the students' academic and behavioral responses. By interpreting students' signs of performance and behavior, the player makes decisions about how to modify instruction to help students succeed on assigned instructional tasks. Increased understanding of the factors that improve students' learning leads the players to make better decisions.

The player of the simulation, acting as the teacher, improves his or her use of teaching strategies through repeated cycles of analyzing student needs, making instructional decisions and evaluating the impact of his/her actions on students' learning in a simulated classroom. SimSchool enables teachers to engage in reflective practice. Reflective practice is a process that allows teachers to (a) stop and think about their practice, (b) analyze classroom decision making, and (c) draw on theory and relate theory back to practice. Critical analysis allows time for a teacher to access existing knowledge and apply that knowledge to the current classroom situation. In addition, teachers have an opportunity to generate new knowledge and ideas. As a result, teachers may modify their classroom interactions (Farrell, 2008). Players are provided with feedback concerning their choices across the variables of academics, agreeableness, intellect, emotion, extroversion and persistence (see figure one). 
- Amazo, Jay
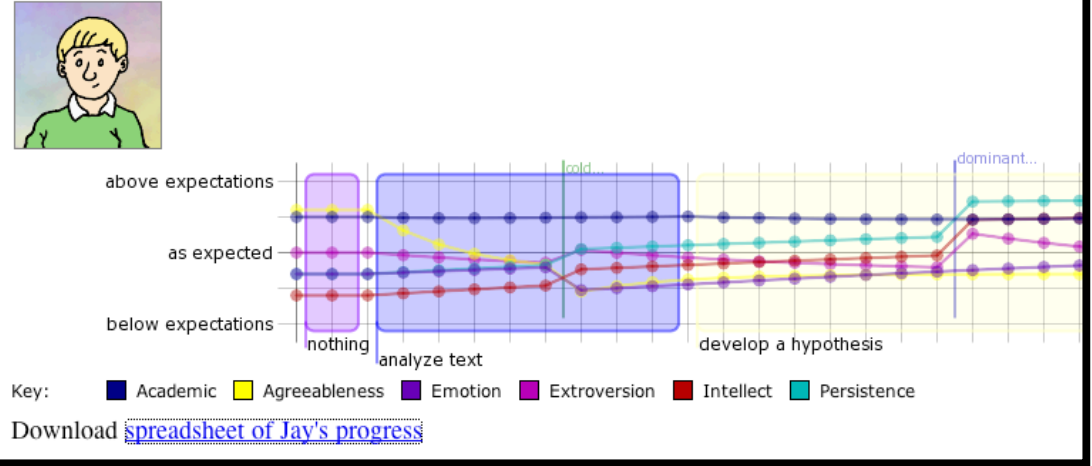

Figure 1. A graphical representation of a student's changes across the variables of academic competence, agreeableness, emotion, extroversion, intellect, and persistence related to instructional modifications.

Using simSchool, a typical classroom from any location in the US can be emulated. With simSchool, any number of unique learners within the inclusive classroom can be simulated. Students with various learning needs, ethnic backgrounds and disabilities can be easily represented within the simulated classroom.

SimSchool also contains a verbal interaction model built on the "Interpersonal Circumplex Theory" (Kiesler, 1983) which proposes that verbal interactions involve both power and affiliation negotiations. The power component ranges from dominant to submissive and the affiliation component ranges from friendly to distant or hostile. The interactions of the variables give rise to 16 pairs of opposites such as "sociable to aloof" that are used to model attitudes in teacher-student interactions.

The model's dynamic equations combine variables in different ways depending on the context and intention of the user, made evident through the range of available options for action. This gives rise to highly differentiated behaviors in the students that are not strictly reproducible from simulation to simulation, but which follow heuristics that can be learned - such as the need to 
individualize instruction for some students in order to have all students succeed.

The modelling paradigm in simSchool works by computing a time series evolution of the classroom as a system. This modelling allows novel dynamics to evolve moment by moment as the user, a teacher candidate, makes decisions. SimSchool promotes thinking on one's feet because class time waits for no one.

The students in simSchool give the teacher indications of both the ease and difficulty of the tasks the students are facing. Teachers quickly learn that a single task placed in front of several students, will most likely not match each student's learning needs, but instead will have subtle differences with each one, and impact each of the students differently. The simulation is dynamic because even if the teacher does nothing (e.g. does not adapt tasks or even simply change tasks), each student's factors continue to change over time in an attempt to meet the task requirements.

\section{Conclusion}

As a result of the dynamic modelling approach, there is a continuous production of moment-by-moment evidence of what the teacher candidate is attempting to do as he or she "teaches" the class. Erikson, Noonan, and McCall (2012) indicate that retaining teachers and accessing professional development have been longstanding struggles for rural school districts, and particular challenges include retaining teachers with special education endorsements. These researchers found that teachers who participated in online professional development gained knowledge, increased personal capacity to apply research-based practices, and implemented research-based transition practices within their classrooms. SimSchool displays characteristics could that fit well into an online training program for rural educators. 


\section{References}

Backlund, P., Engstrom, H., Johannesson, M., \& Lebram, M.

(2010). Games for traffic education: An experimental study of a game-based driving simulator. Simulation \& Gaming, 41(2), 145.

Barnet, B., \& Hirsch (2005). Recruiting and retaining teachers for hard-to-staff schools. Issue Brief, NGA Center for Best Practices, Washington, DC.

Billingsley, B., Carlson, E., \& Klein, S. (2004). The working conditions and induction support of early career special educators. Exceptional Children, 70(3), 333-347.

Bush, L. \& Hall, J. (2013). Rethinking Pre-Service Teacher Training: Lessons Learned with simSchool. In R. McBride \& M. Searson (Eds.), Proceedings of Society for Information Technology \& Teacher Education International Conference 2013 (pp. 2550-2553). Chesapeake, VA: AACE.

Erickson, A. S., Noonan, P. M., \& McCall, Z. (2012). Effectiveness of online professional development for rural special educators. Rural Special Education Quarterly, $31(1), 22-32$.

Farrell, S. C. (2008). Reflective practice in the professional 
development of teachers of adult English learners. CAELA Network Brief, Retrieved from

http://www.cal.org/caelanetwork/pdfs/ReflectivePracticeFi nalWeb.pdf

Fowler, S. M., \& Pusch, M. D. (2010). Intercultural simulation games: A review (of the United States and beyond). Simulation \& Gaming, 41(1), 94-115.

Gehrke, R. S., \& McCoy, K. (2007). Considering the context: Differences between the environments of beginning special educators who stay and those who leave. Rural Special Education Quarterly, 26(3), 32-40.

Hopper, S., Knezek, G., \& Christensen, R. (2013). Assessing Alignment of Pedagogical Experience and Confidence in a Simulated Classroom Environment. In R. McBride \& M. Searson (Eds.), Proceedings of Society for Information Technology \& Teacher Education International Conference 2013 (pp. 2870-2876). Chesapeake, VA: AACE.

Johnson, E. S., Humphrey, M. J., \& Allred, K. W. (2009). Addressing the shortage of rural special educators through technology and collaboration. Rural Special Education Quarterly, 28(2), 17-21. 
Kiesler, D. (1983). The 1982 interpersonal circle: A taxonomy for complementarity in human transactions. Psychological Review, 90 (3), 185-214.

Lowe, (2006). Rural Education: Attracting and retaining teachers in small schools. The Rural Educator, 27(2), 28-32.

McPherson, R., Tyler-Wood, T., McEnturff Ellison, A. \& Peak, P. (2011). Using a Computerized Classroom Simulation to Prepare Pre-Service Teachers. Journal of Technology and Teacher Education, 19(1), 93-110.

Peak, P., McPherson, R., Barrio, B., Knezek, G., Ellison, A. \& Christensen, R. (2009). Perceptions of Special Education Pre-Service and In-service Teachers. In I. Gibson et al. (Eds.), Proceedings of Society for Information Technology \& Teacher Education International Conference 2009 (pp. 3976-3981). Chesapeake, VA:

\section{AACE.}

Reckien, D., \& Eisenack, K. (2010). Urban sprawl: Using a game to sensitize stakeholders to the interdependencies among actors' preferences. Simulation \& Gaming, 41(2), 260 277.

Rural Policy Matters. (2001). A newsletter of rural school and community action, 2001, Vol. 3, No. 1-11.

Smith, R. (2010). The long history of gaming in military training. 
Simulation Gaming, 41(1), 6-19.

Williams, J. M., Martin, S. M., \& Hess, R. K. (2010). Personnel preparation and service delivery issues in rural areas: The state of the art. Rural Special Education Quarterly, 29(4), 31-39.

Zyda, M. (2005). From visual simulation to virtual reality to games. Computer, 38(9), 25-32. 